\title{
Darwin's Tubercle
}

Philip R. Cohen

$$
\text { حديبة دارون }
$$

فيليب كوهين
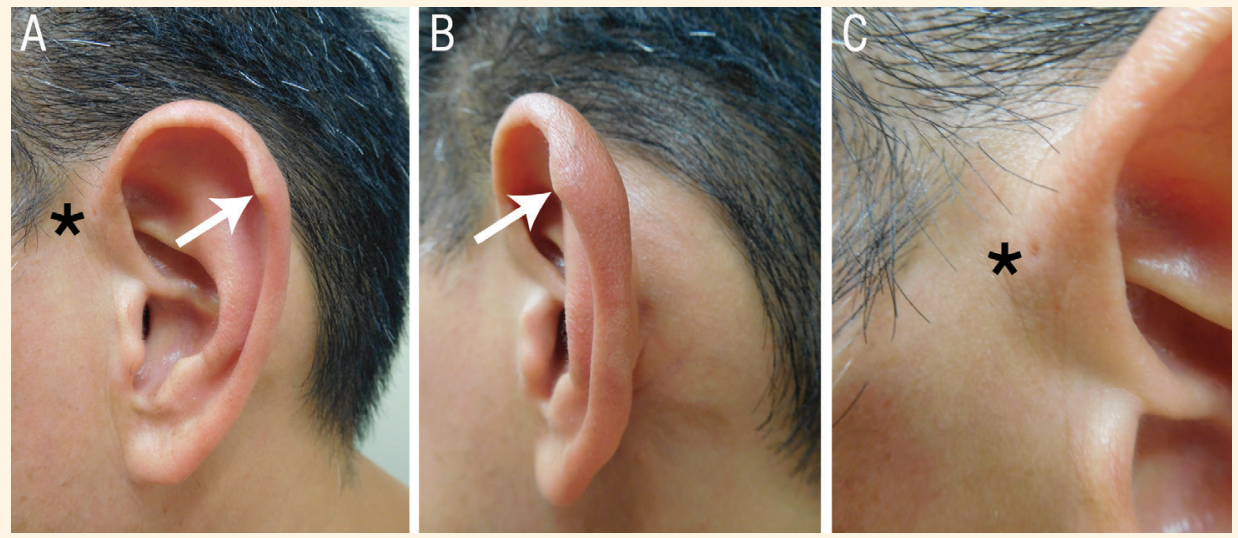

Figure 1: Photographs of the left ear of a 47-year-old man showing (A) a Darwin's tubercle presenting as (B) a prominence of the posterior-superior helix (arrows). In addition, (C) a preauricular pit (asterisk) was observed.

A HEALTHY 47-YEAR-OLD MAN PRESENTED to the dermatology office of the University of California San Diego, La Jolla, California, USA, in 2017 for a complete examination of his skin. On the posterior-superior helix of his left ear, an asymptomatic firm elastotic triangular prominence of skin-covered cartilage was observed, measuring 10 x 10 × 22 mm [Figures $1 \mathrm{~A}$ and $\mathrm{B}$ ]. In addition, there was a cutaneous pit in the left preauricular area [Figure 1C]. A similar yet less pronounced helical tubercle was also present on his right ear. The patient had no family history of auditory or renal impairment.

\section{Comment}

Darwin's tubercle is a benign and unique helical feature that often appears as a solitary peculiarity on the ear but can also present bilaterally on both ears. ${ }^{1}$ While the condition requires no additional evaluation or treatment, surgical treatment-consisting of a fullthickness excision of the skin and the prominent cartilage underneath - may be considered in order to address cosmetic concerns. In addition to Darwin's tubercle, other peculiarities of the helix include pointy ear, satyr ear and Stahl's ear deformity. ${ }^{1,2}$ Although Darwin's tubercle usually occurs alone, it has been associated with accessory tragus, congenital absence of the helix and weathering nodules. ${ }^{1,2}$

Isolated preauricular pits are a congenital anomaly with an incidence of 5-10 cases per 1,000 newborns. ${ }^{3}$ According to recent research, hearing tests or a urinalysis are not recommended for patients with preauricular pits unless the individual has an associated syndrome or a family history of auditory or renal impairment. ${ }^{3,4}$ Therefore, the current patient did not require any additional evaluation or treatment of his preauricular pit.

Darwin's tubercles contribute to the individuality of human ears and may have applications in the fields of personal identification or forensic sciences. ${ }^{1}$ The presence of Darwin's tubercle has not been associated with any significant adverse clinical consequences or systemic anomalies, including chondrodermatitis or hearing and urinary anomalies. The concurrent presence of Darwin's tubercle and a preauricular pit of the ipsilateral ear, such as that observed in the present case, may represent a coincidental occurrence rather than an association between the two conditions. 


\section{References}

1. Loh TY, Cohen PR. Darwin's tubercle: Review of a unique congenital anomaly. Dermatol Ther (Heidelb) 2016; 6:143-9. doi: 10.1007/s13555-016-0109-6.

2. Lykoudis EG, Seretis K, Spyropoulou GA. A 6-year experience in flat helix correction with a simple procedure. Arch Facia Plast Surg 2011; 13:168-72. doi: 10.1001/archfacial.2011.31.
3. Firat Y, Sireci S, Yakinci C, Akarçay M, Karakaș HM, Firat AK, et al. Isolated preauricular pits and tags: Is it necessary to investigate renal abnormalities and hearing impairment? Eur Arch Otorhinolaryngol 2008; 265:1057-60. doi: 10.1007/s004 05-008-0595-y.

4. Kugelman A, Hadad B, Ben-David J, Podoshin L, Borochowitz Z, Bader D. Preauricular tags and pits in the newborn: The role of hearing tests. Acta Paediatr 1997; 86:170-2. doi: 10.1111/ j.1651-2227.1997.tb08860.x 